Research Article

\title{
Assessment of Climate Change Impacts on Extreme Precipitation Events: Applications of CMIP5 Climate Projections Statistically Downscaled over South Korea
}

\author{
Jang Hyun Sung, ${ }^{1}$ Hyung-Il Eum, ${ }^{2}$ Junehyeong Park ${ }^{D},{ }^{3}$ and Jaepil Cho ${ }^{4}$ \\ ${ }^{1}$ Ministry of Environment, Han River Flood Control Office, Seoul, Republic of Korea \\ ${ }^{2}$ Alberta Environment and Parks, Calgary, Canada \\ ${ }^{3}$ Civil, Construction, and Environmental Engineering, University of Alabama, Tuscaloosa, AL, USA \\ ${ }^{4}$ Climate Services and Research Department, APEC Climate Center, Busan, Republic of Korea
}

Correspondence should be addressed to Junehyeong Park; sai0259@gmail.com

Received 26 April 2018; Revised 14 August 2018; Accepted 16 September 2018; Published 23 October 2018

Academic Editor: Stefano Dietrich

Copyright $\odot 2018$ Jang Hyun Sung et al. This is an open access article distributed under the Creative Commons Attribution License, which permits unrestricted use, distribution, and reproduction in any medium, provided the original work is properly cited.

\begin{abstract}
Climate change may accelerate the water cycle at a global scale, resulting in more frequent extreme climate events. This study analyzed changes in extreme precipitation events employing climate projections statistically downscaled at a station-space scale in South Korea. Among the CMIP5 climate projections, based on spatial resolution, this study selected 26 climate projections that provide daily precipitation under the representative concentration pathway (RCP) 4.5. The results show that a 20 -year return period of precipitation event during a reference period (1980 2005) corresponds to a $16.6 \mathrm{yr}$ for 2011 to $2040,14.1 \mathrm{yr}$ for 2041 to 2070 , and $12.8 \mathrm{yr}$ for 2071 to 2100 , indicating more frequent extreme maximum daily precipitation may occur in the future. In addition, we found that the probability density functions of the future periods are located out of the $10 \%$ confidence interval of the PDF for the reference period. The result indicates that the design standard under the reference climate is not managed to cope with climate change, and accordingly the revision of the design standard is required to improve sustainability in infrastructures.
\end{abstract}

\section{Introduction}

Changes in the water cycle caused by climate change lead to temporal and spatial alteration in hydrological and ecological systems. Although climate models provide essential information to assess climate change impacts at a global scale, direct applications of climate projections have inherent problems due to a coarse resolution $(\sim 100 \mathrm{~km})$ which induce a difficulty to capture climatic characteristics at regional or local scales. Therefore, an application of downscaling technique is a prerequisite to accurately complete climate change studies at a local scale. Since there is, in addition, considerable uncertainty in climate projections, caused by different dynamic systems, grid size, and parameterization of physics processes, many studies have paid attention to quantify uncertainty of climate change scenarios in climate change impact assessment [1-4].

An ensemble approach has been applied to deal with the uncertainty in climate scenarios because a specific scenario cannot represent all possible future climate conditions $[5,6]$. However, it is still questionable in the climate change impact assessment which scenarios need to be included to capture future climate variability. Most studies have selected appropriate scenarios based on the performance in reproducing historical climate. However, it has the limitation that performance during a historical period cannot guarantee consistent performance during a future period [7]. The IPCC (Intergovernmental Panel of Climate Change) report suggested the use of as many climate scenarios as possible in climate change assessment [8]. In other words, employing multiple scenarios in climate change impact assessment may take into account the uncertainty. Therefore, the use of multimodel ensemble (MME) has been increasing to capture possible climate changes projected by multiple models [9-11].

Previous studies have assessed the changes in extreme precipitation and suggested that South Korea is expected to become more vulnerable to flood hazards due to an increase 
in the probability of severe extreme events in the future $[12,13]$. Sung et al. [13] found overall increase in frequency of extreme precipitation over South Korea in association with climate change. According to [13]; particularly, daily extreme precipitation with 20 -year return period during the reference climate from 1980 to 2005 is likely to happen about every 4.3 and $3.4 \mathrm{yr}$ by the end of 21 st century (2070 2099) employing HadGEM3-RA based on the RCP 4.5 and 8.5. Ahn et al. [14] suggested that multi-RCMs can be used to reduce uncertainties and assess the future change of extreme precipitation more reliably. According to [14], 50-year return value will change from $-32.69 \%$ to $72.7 \%$ and from $-31.6 \%$ to $96.32 \%$ in the mid-21st century and from $-31.97 \%$ to $86.25 \%$ and from $-19.45 \%$ to $134.88 \%$ in the late-21st century under RCP 4.5 and 8.5 scenarios. Im et al. [15] suggested that changes in return levels of annual maximum precipitation in a regional climate model indicate an increased frequency of present day in 20- and 50-year extreme precipitation events. Previous studies have projected future extreme precipitations with one or several models produced by dynamic downscaling.

In general, evaluating changes in extreme events in the future requires high-resolution climate change scenarios which are produced by dynamic or statistical downscaling methods. Especially in South Korea, spatial downscaling should be implemented because the climate of South Korea is highly dependent on topography, due to the large portion of mountainous area. The dynamic downscaling takes advantage of considering interaction between climatic systems, the nonstationarity of climate change, and the temporal and spatial correlation between variables which can be interpreted as a physics process of the Earth system [13, 16-19]. However, the dynamic downscaling techniques require a huge computing facility and highly skilled experts. On the other hand, statistical downscaling directly incorporates correlations between climate models' simulations and observational data into algorithms. Therefore, statistical downscaling techniques are inexpensive to apply to convert low-resolution into high resolution. Although statistical downscaling has the limitation that it assumes the stationarity of the climate processes over time, statistical downscaling methods have been actively applied to produce a high-resolution regional climate projections [20-25]. The recent NEX-GDDP (NASA Earth Exchange Global Daily Downscaled Projections) and DCHP (Downscaled CMIP3 and CMIP5 Climate and Hydrology Projections) applied bias-correction/spatial disaggregation (BCSD) [25] for climate change impact assessment at local scales. Abatzoglou and Brown [20] suggested multivariate adaptive constructed analogs (MACA) to improve coincidence of climate events. Burger et al. [21] proposed detrended quantile mapping (DQM) and [24] applied spatial disaggregation/quantile delta mapping (SD-QDM) to preserve long-term trends driven by climate models.

There are limitations in establishing adaption and response to climate change due to different information produced by each climate change model, physical processes, and resolutions. Furthermore, extreme values are associated with large uncertainty so that it is unwise to use the result of statistical frequency analysis using climate change scenarios naively. Therefore, in this study, we applied the downscaling preserving the long-term trend of the climate model to 26 RCP 4.5 scenarios and projected the change in extreme precipitation-the 20-year return value of annual maximum daily precipitation-over South Korea and estimated the uncertainty with the confidence intervals.

\section{Data and Method}

2.1. Procedure. In this study, we used MME, which combines multiple model results, to project changes in extreme precipitation in South Korea (Figure 1). Employing the daily precipitation of 26 CMIP5 climate projections downscaled by three statistical downscaling methods, we collected the annual maximum daily precipitation. Then, we estimated the frequency and magnitude of extreme precipitation using the generalized extreme value (GEV) distribution for the reference period (1980 2005) and the three 30-year future periods (Future1: 2011 2040, Future2: 2041 2070, and Future3: 2071 2100).

2.2. Climate Change Scenarios. The uncertainties among scenarios should be taken into consideration, since adaptation strategies were different depending on whether a specific scenario was selected [26]. Climate change scenarios have different simulations due to GCMs with different dynamics and grid sizes and parameterization processes. Therefore, the use of a single model is likely to lead to a bias, so it is necessary to consider the uncertainties using GCM results. As an alternative to this, the use of MME has been increasing. The Coupled Model Intercomparison Project (CMIP) started in 1995 to compare various climate models. In CMIP Phase 5 (CMIP5), 4 representative concentration pathways (RCP) were proposed considering economic growth rate, industrialization and restoration technology. In this study, we used the RCP 4.5 scenario, in which the greenhouse gas mitigation policy is quite substantial. RCP 4.5 is a scenario that stabilizes a radiative forcing of $4.5 \mathrm{~W} \cdot \mathrm{m}^{-2}$ in 2100 without exceeding this value. Table 1 shows the 26 GCMs selected in the previous climate change studies $[24,27]$ in descending order of spatial resolution, where grid points are collected within $\mathrm{E} 119^{\circ}-135^{\circ}$ and $\mathrm{N} 29^{\circ}-43^{\circ}$. Using climate projections at the grid points of each GCM, we applied three statistical downscaling methods to downscale to the automated synoptic observing system (ASOS) stations in Figure 2.

2.3. Statistical Downscaling. In this research, three statistical downscaling methods are used. The first method used in this research is spatial disaggregation/quantile mapping (SDQM), which is equal to the daily BCSD [20]. This method is suggested to overcome the shortcoming of existing typical method, BCSD, that it may lose the climate characteristics in climate model driven daily sequencing. Moreover, spatial disaggregation/detrended quantile mapping (SD-DQM) and spatial disaggregation/quantile delta mapping (SD-QDM) are also applied to preserve GCM-driven long-term trends. More specific explanations and citations are shown below. 


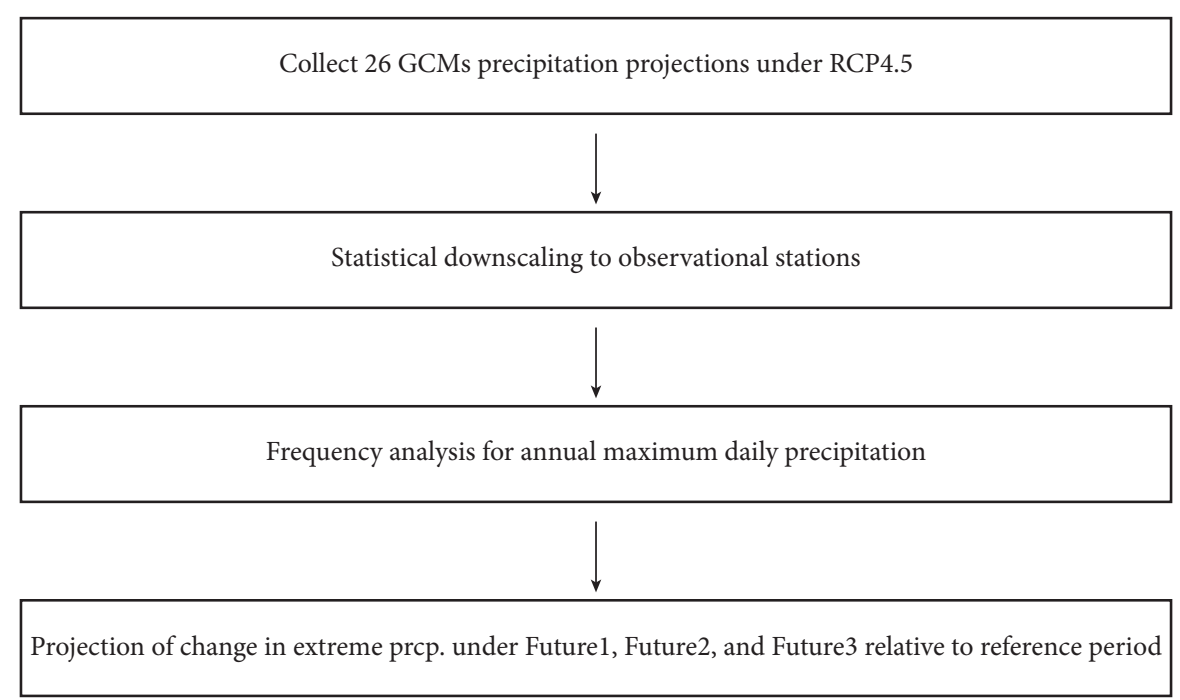

Figure 1: Procedure of this study.

TABLE 1: 26 GCMs of CMIP5 for this study.

\begin{tabular}{|c|c|c|c|c|}
\hline No. & GCMs & Resolution (degree) & Grid points & Institution \\
\hline 1 & CMCC-CM & $0.750 \times 0.748$ & $22 \times 18$ & \multirow{4}{*}{ Centro Euro-Mediterraneo per I Cambiamenti Climatici } \\
\hline 2 & CCSM4 & $1.250 \times 0.942$ & $13 \times 15$ & \\
\hline 3 & CESM1-BGC & $1.250 \times 0.942$ & $13 \times 15$ & \\
\hline 4 & CESM1-CAM5 & $1.250 \times 0.942$ & $13 \times 15$ & \\
\hline 5 & BCC-CSM1-1-M & $1.125 \times 1.122$ & $15 \times 12$ & $\begin{array}{c}\text { Beijing Climate Center, China Meteorological } \\
\text { Administration }\end{array}$ \\
\hline 6 & MRI-CGCM3 & $1.125 \times 1.122$ & $15 \times 12$ & Meteorological Research Institute \\
\hline 7 & CNRM-CM5 & $1.406 \times 1.401$ & $12 \times 12$ & \multirow{2}{*}{$\begin{array}{c}\text { Centre National de Recherches Meteorologiques } \\
\text { Atmosphere and Ocean Research Institute (The } \\
\text { University of Tokyo) }\end{array}$} \\
\hline 8 & MIROC5 & $1.406 \times 1.401$ & $12 \times 10$ & \\
\hline 9 & HadGEM2-AO & $1.875 \times 1.250$ & $9 \times 11$ & \multirow{3}{*}{ Met Office Hadley Centre } \\
\hline 10 & HadGEM2-CC & $1.875 \times 1.250$ & $9 \times 11$ & \\
\hline 11 & HadGEM2-ES & $1.875 \times 1.250$ & $9 \times 11$ & \\
\hline 12 & INM-CM4 & $2.000 \times 1.500$ & $8 \times 10$ & Institute for Numerical Mathematics \\
\hline 13 & IPSL-CM5A-MR & $1.875 \times 1.865$ & $7 \times 11$ & Institut Pierre-Simon Laplace \\
\hline 14 & CMCC-CMS & $1.875 \times 1.865$ & $9 \times 7$ & Centro Euro-Mediterraneo per I Cambiamenti Climatici \\
\hline 15 & MPI-ESM-LR & $1.875 \times 1.865$ & $9 \times 7$ & Max Planck Institute for Meteorology (MPI-M) \\
\hline 16 & MPI-ESM-MR & $1.875 \times 1.865$ & $9 \times 7$ & \\
\hline 17 & FGOALS-s2 & $2.813 \times 1.659$ & $6 \times 9$ & Academy of Sciences \\
\hline 18 & NorESM1-M & $2.500 \times 1.895$ & $7 \times 8$ & Norwegian Climate Centre \\
\hline 19 & GFDL-ESM2G & $2.500 \times 2.023$ & $6 \times 7$ & \multirow{4}{*}{$\begin{array}{c}\text { Geophysical Fluid Dynamics Laboratory } \\
\text { Institute Pierre-Simon Laplace }\end{array}$} \\
\hline 20 & GFDL-ESM2M & $2.500 \times 2.023$ & $6 \times 7$ & \\
\hline 21 & IPSL-CM5A-LR & $3.750 \times 1.895$ & $5 \times 8$ & \\
\hline 22 & IPSL-CM5B-LR & $3.750 \times 1.895$ & $5 \times 8$ & \\
\hline 23 & BCC-CSM1-1 & $2.813 \times 2.791$ & $6 \times 5$ & $\begin{array}{c}\text { Beijing Climate Center, China Meteorological } \\
\text { Administration }\end{array}$ \\
\hline 24 & CanESM2 & $2.813 \times 2.791$ & $6 \times 5$ & Canadian Centre for Climate Modelling and Analysis \\
\hline 25 & MIROC-ESM-CHEM & $2.813 \times 2.791$ & $6 \times 5$ & \multirow{2}{*}{ Japan Agency for Marine-Earth Science and Technology } \\
\hline 26 & MIROC-ESM & $2.813 \times 2.791$ & $6 \times 5$ & \\
\hline
\end{tabular}

2.3.1. Spatial Disaggregation/Quantile Mapping (SDQM). BCSD has been originally developed to downscale GCM's information to regional climate data at the monthly scale, and a temporal disaggregation technique is applied to generate bias-corrected daily climate data [25]. Therefore, it may lose the climate characteristics in climate model driven daily sequencing. Therefore, a daily BCSD has been applied not only to avoid the temporal disaggregation process but also to preserve climate model driven daily sequencing by incorporating cumulative density function (CDFs) of daily climate data $[20,28]$. In the daily BCSD, the spatial disaggregation of the climate information is first performed by the inverse distance weighted interpolation [29] in which the squared distance between the GCM grid and the observation 


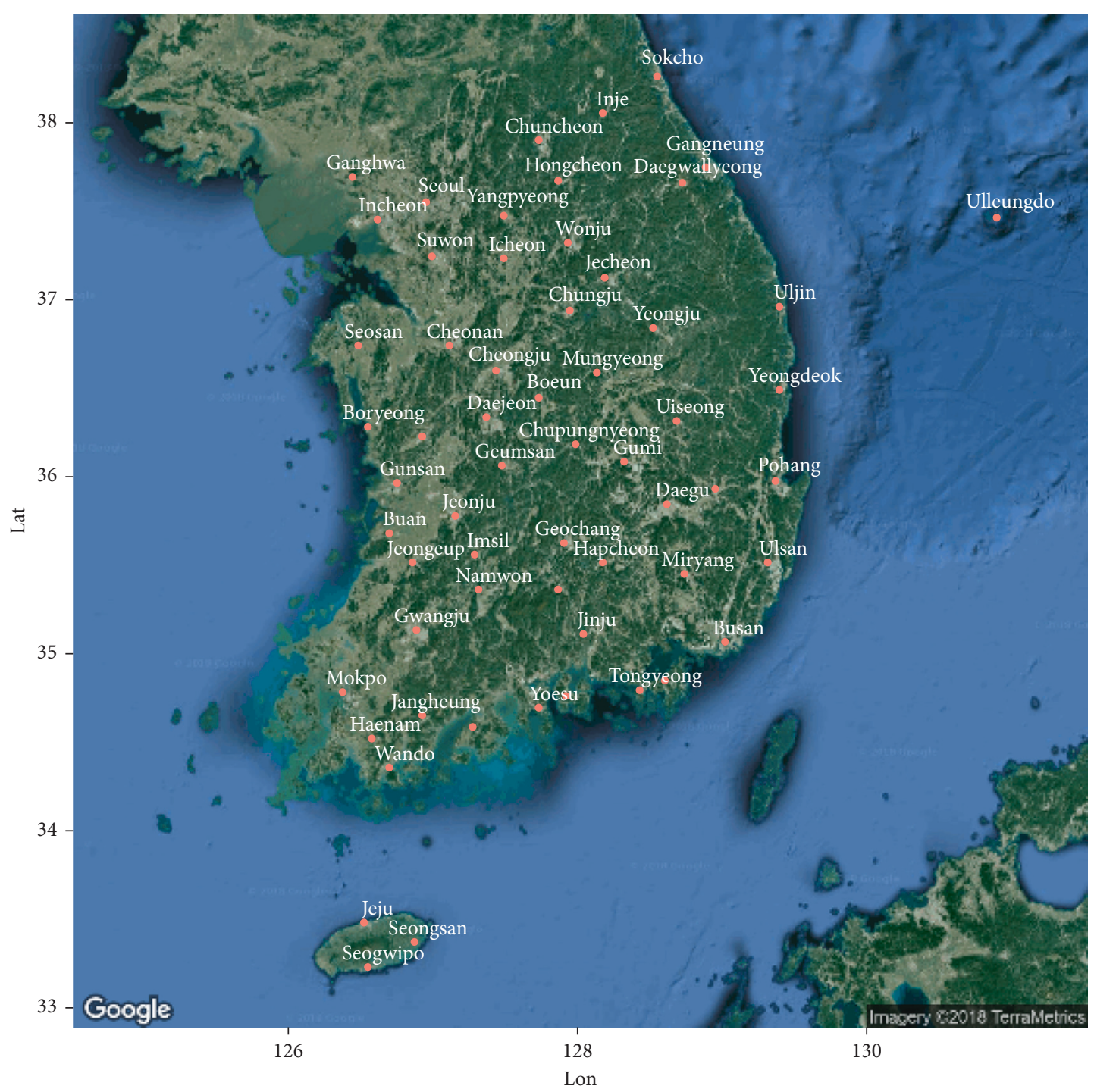

Figure 2: ASOS 60 weather stations in South Korea.

point is inversely weighted. Then, the bias correction is performed using the quantile delta algorithm shown in Equation (1) using empirical CDFs formulated with daily climate data within a moving window to reflect the seasonality of the area. Eum and Cannon [24] tested different half-widths of moving window, for example, 15, 30, 90, and 180 days, to investigate the impacts of moving window selection on extreme climate indices. The study showed that a 15-day moving window reflected better seasonality on the climate index for South Korea. Therefore, this study also employed the same moving window $(15 \mathrm{~d})$ for the quantile mapping method. For example, when downscaling for January 1, the density function is formed by observational and GCM data from December 15 to January 16, and this is applied to Equation (1) to bias-correct. In this study, daily BCSD was applied and will be referred to as SDQM.

$$
\widehat{x}_{m, p}(t)=F_{o, h}^{-1}\left[F_{m, h}\left\{x_{m, p}(t)\right\}\right] \text {, }
$$

where $x_{m, p}(t)$ and $\widehat{x}_{m, p}(t)$ represent the values before and after the bias correction at time $t$, respectively, $F_{m, h}(t)$ represents the cumulative density function of the past period generated by the global model, and $F_{o, h}^{-1}$ represents the inverse function of the cumulative density function of the observed data. For Equation (1), $p$ is the projection, $h$ is the past period, $m$ is the global model, and $o$ is the observation.

\subsubsection{Long-Term Trend Preserving Downscaling Method.} Extreme values outside of a range of historical data need to be extrapolated in SDQM. Eum and Cannon [24] estimated bias-corrected values using the Gumbel distribution which has been used to evaluate extreme flood events for South Korea due to simplicity in estimating parameters. This study also used the same method to extrapolate values outside of the historical range. For climate data with GCM-driven long-term (increasing or decreasing) trends, such as temperature, more extreme events may occur, and accordingly more frequent extrapolation has to be implemented, which may induce a substantial distortion of GCM-driven climate signals by the variance inflation [24, 30, 31]. Burger et al. [21] proposed the detrended quantile mapping (DQM) method 
that removes a long-term trend in climate projections to minimize the frequency of extrapolation. While DQM can directly consider the long-term trend of the monthly average, it cannot consider the long-term trend of the extreme values. Cannon et al. [22] proposed quantile delta mapping (QDM) designed to preserve absolute or relative changes in all of quantiles. As in [24], this study applied SD-QDM that combined the daily BCSD and QDM to produce downscaled climate projections over South Korea. More details on SDQDM can be found in [24]. The CMIP5 historical run was simulated until 2005, and future climate scenarios were simulated from 2006 to 2100 forced by RCPs. Therefore, this study set the reference period from 1976 to 2005. For the future period, SD-QDM was applied for a total of $30 \mathrm{yr}$ from $15 \mathrm{yr}$ before to $14 \mathrm{yr}$ after a certain year to consider gradual changes in quantiles between the reference and future periods. For example, when applying QDM for 2006, the reference period was from 1976 to 2005 , and the future period was from 1991 to 2020 .

2.4. Frequency Analysis. Generally, if a certain precipitation is equaled or exceeded once during an average $T$ year, it is said to have a return period $T$. The inverse of the return period $T$ is an exceedance probability $(P)$ of the event occurring in a certain year:

$$
T=\frac{1}{P} .
$$

The GEV distribution function is generally used to estimate the nonexceedance probability of extreme events because the upper tail of the GEV distribution is suitable to represent the extreme events. The GEV distribution has been used to describe the extreme probability in observed or GCM simulated hydrometeorological variables [32-34], because there is much evidence that the distributions of hydrologic variables have heavy tails. Although it can be difficult to determine from only a single site unless the record is relatively long, the distribution of annual maximum precipitation amount appears consistently to have a heavy tail [35-37]. Because GEV has shape parameters and is very useful for expressing heavy tail, we used the GEV distribution in this study. The cumulative distribution function, which estimates the nonexceedance probability of the GEV distribution, is given by Equation (3) and its solution is estimated using (4) [38]:

$$
\begin{gathered}
F(x)= \begin{cases}\exp \left[-\left(1-\kappa \frac{x-\xi}{\alpha}\right)^{1 / \kappa}\right], & \kappa \neq 0, \\
\exp \left[-\exp \left(-\frac{x-\xi}{\alpha}\right)\right], & \kappa=0,\end{cases} \\
x= \begin{cases}\xi+\frac{\alpha}{\kappa}\left\{1-[-\log (P)]^{\kappa}\right\}, & \kappa \neq 0, \\
\xi-\alpha \log [-\log (P)], & \kappa=0,\end{cases}
\end{gathered}
$$

where $\xi, \alpha$, and $\kappa$ are parameters related to location, scale, and shape, respectively. The GEV distribution can be divided into type I, type II, and type III distributions according to the sign of $\kappa$. Among them, type I is called Gumbel and type III is called Weibull distribution. In Equations (3) and (4) the range of the variable $x$ depends on $\kappa$, which is $\xi+\alpha / \kappa \leq x<\infty$ for $\kappa<0,-\infty<x<\infty$ for $\kappa=0$, and $-\infty<x \leq \xi+\alpha / \kappa$ for $\kappa>0$ [38]. The GEV distribution varies in the thickness of the upper tail depending on the $\kappa$. In other words, $\kappa$ is getting smaller when the tail area of distribution function enlarges, which means that the occurrence probability of the extreme value increases. Also, most of annual maximum 24-hour precipitations are located in the interval where the $\kappa$ are negative [39]. For $\kappa<0$, the distribution has a thicker right-hand tail. We used the GEV type II distribution.

The estimation methods of the parameters of the GEV distribution include the method of moments, the method of maximum likelihood estimates, the method of probability weighted moments, and the method of L-moments. The method of moments is simple to calculate, but the higher the moments, the more inaccurate estimates are obtained. The maximum likelihood method is effective when the number of sample data is large enough, but the solution process is complicated and sometimes the solution cannot be obtained because it does not converge. Since the probability weighted moment method and the L-moment method are based on the same theory, the same result is obtained. They are not sensitive to the number of sample data because they use the order statistics of the observation data. In addition, even with distorted data, relatively stable results can be obtained [39]. In this study, the method of L-moment was applied to estimate the parameters of the GEV distribution. 20-year return value of annual maximum daily precipitation, which is referred to as 20-year precipitation in this study, is selected for target of this study because length of each projection period is 30 years so that we need extrapolation for events with return periods exceeding 30 years and Klein Tank et al. [40] suggested 20-year event for evaluating the intensity and frequency of rare events that lie far in the tails of the probability distribution of weather variables.

\section{Results}

3.1. Future Projection. The spatial distributions of the 20year precipitation averaged over 26 climate projections are shown in Figure 3 to identify regional variation of extreme precipitation during the reference and future periods. Spatial downscaling methods applied in Figure 3 were SDQM, SDDQM, and SD-QDM. The average of 20-year precipitation for the 26 CMIP5 GCMs changed gradually from the reference period to the Future1, Future2, and Future3 periods. Therefore, Figure 3 only includes the reference period as a start point, the Future 3 period as an end point, and the difference between these two periods. At the northeastern mountainous region and southern coastal regions, large extreme precipitation was projected due to their regional characteristics. These regions receive more precipitation by the effects of mountains, urbanization, and ocean climates [41].

In order to quantitatively examine the difference in results by the method of downscaling shown in Figure 3, the spatially averaged precipitation of South Korea was calculated for each downscaling method (Table 2). The table 


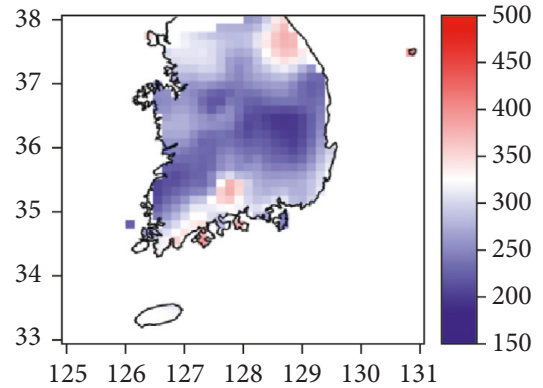

(a)

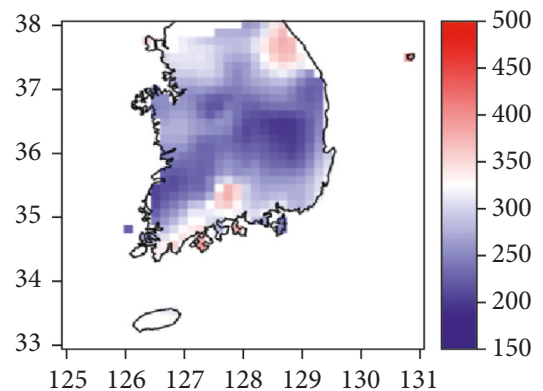

(d)

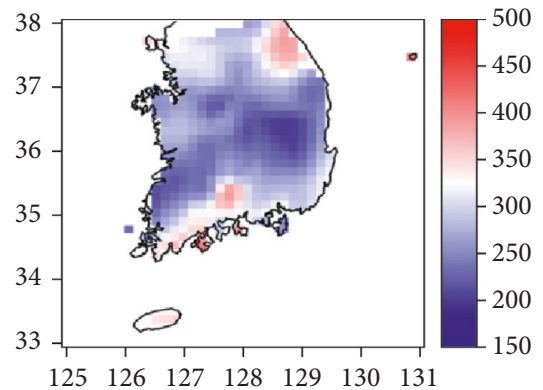

(g)

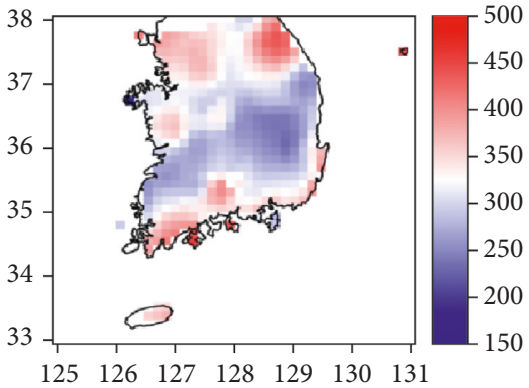

(b)

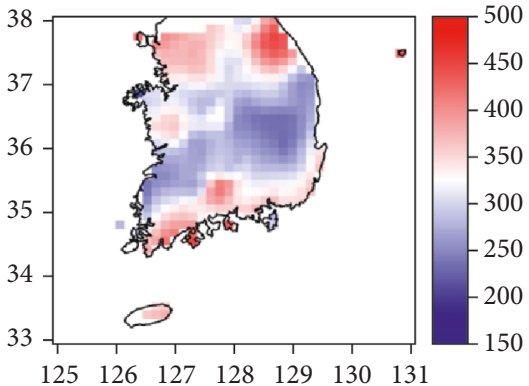

(e)

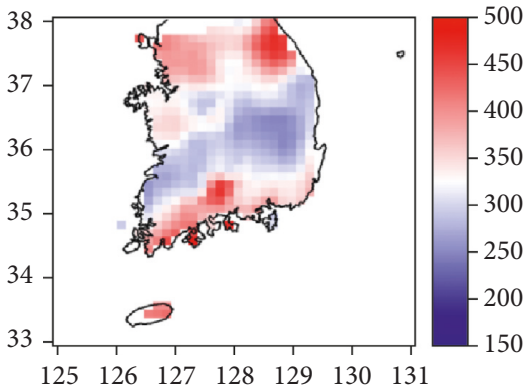

(h)

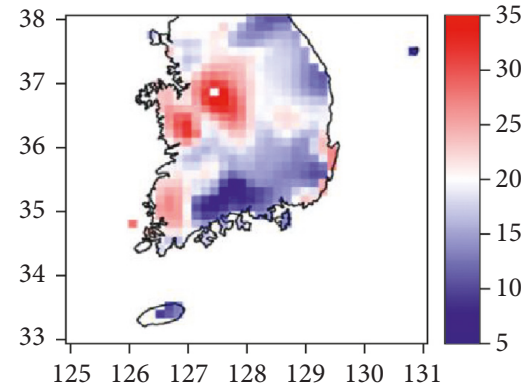

(c)

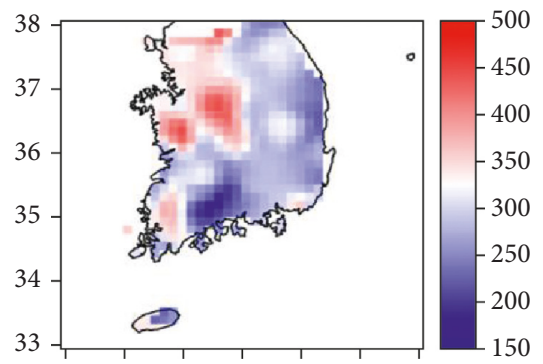

$\begin{array}{lllllll}125 & 126 & 127 & 128 & 129 & 130 & 131\end{array}$

(f)

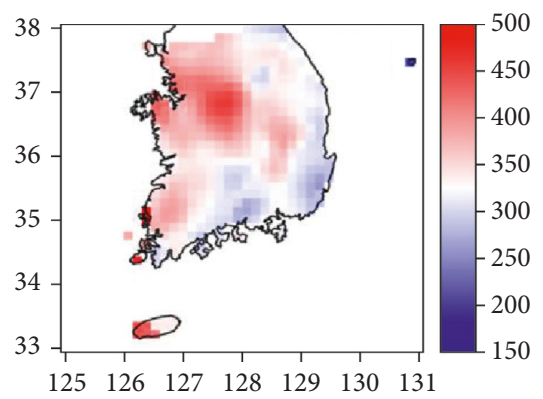

(i)

FIGURE 3: Average of 20-year return value of annual maximum daily precipitation for CMIP5 26 GCMs by SDQM ((a), (b), and (c)), SD$\operatorname{DQM}((\mathrm{d}),(\mathrm{e})$, and $(\mathrm{f}))$ and SD-QDM $((\mathrm{g}),(\mathrm{h})$, and $(\mathrm{i}))$ for the reference $((\mathrm{a}),(\mathrm{d})$, and $(\mathrm{g}))$, Future3 period $((\mathrm{b}),(\mathrm{e})$, and $(\mathrm{h}))$, and the difference between reference and Future3 period in percentage $((\mathrm{c}),(\mathrm{f})$, and $(\mathrm{i}))$.

Table 2: Average of 20-year precipitation under reference, Future1, Future2, and Future3 period for South Korea.

\begin{tabular}{|c|c|c|c|c|c|c|c|c|c|c|c|c|}
\hline & \multicolumn{12}{|c|}{20 -year return value of annual maximum daily precipitation $\left(\mathrm{mm} \cdot \mathrm{day}^{-1}\right)$} \\
\hline & \multicolumn{3}{|c|}{ Reference } & \multicolumn{3}{|c|}{ Future1 } & \multicolumn{3}{|c|}{ Future2 } & \multicolumn{3}{|c|}{ Future3 } \\
\hline & SDQM & SD-DQM & SD-QDM & SDQM & SD-DQM & SD-QDM & SDQM & SD-DQM & SD-QDM & SDQM & SD-DQM & SD-QDM \\
\hline Avg. & 280.4 & 280.4 & 288.0 & 307.2 & 300.7 & 316.2 & 331.0 & 328.2 & 344.2 & 330.7 & 330.0 & 350.0 \\
\hline Med. & 275.2 & 275.2 & 280.5 & 303.7 & 296.3 & 303.8 & 326.5 & 327.0 & 327.6 & 327.2 & 321.7 & 335.2 \\
\hline
\end{tabular}

shows that the amount of precipitation downscaled with SDQDM in the reference and each future period is generally larger than for the other methods. Comparing the mean and median of all the downscaling methods, including SD-QDM, the mean was greater than the median. Therefore, the right tail of the probability density function was thick. Overall, the results in Table 2 mean that 20 -year precipitation in the reference period can occur more frequently in the future. Regarding the difference between the statistical methods, the amount of precipitation downscaled with SD-QDM was larger than other methods by better preserving GCM-driven relative change as shown in Figure 3(i).
The coefficient of variation $(\mathrm{CV})$ was calculated to compare the distribution of 20-year precipitation derived from 26 GCMs (Figure 4). The variance of GCMs in the reference climate was small and differences among sites were relatively small (see Figure 4(a), 4(d), and 4(g)). There was a slight nonstationarity in the spatial distribution of the CV. The area of large CV was broader in the Future 2 and the Future 3 than Future1, indicating that the uncertainty in climate projections may considerably contribute to the distribution of 20-year precipitation in the future. The CV of southeastern (Future1), northeastern (Future2), and southeastern (Future3) region was large. Because the coefficients of variation in the reference 


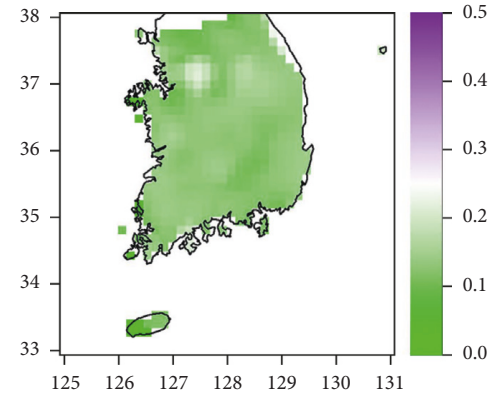

(a)

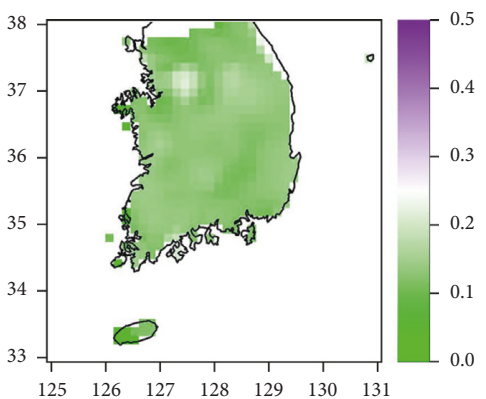

(d)

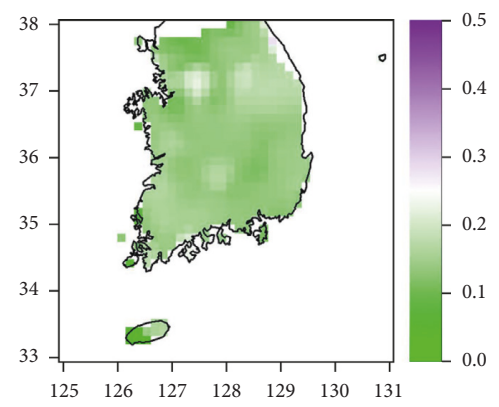

(g)

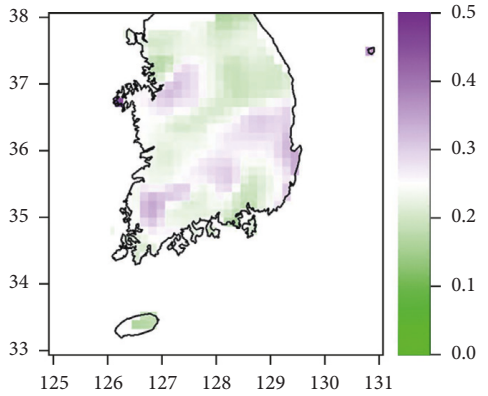

(b)

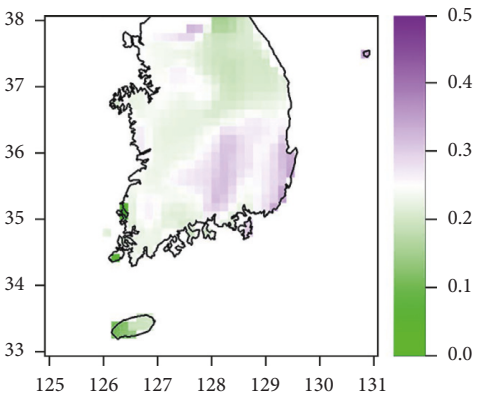

(e)

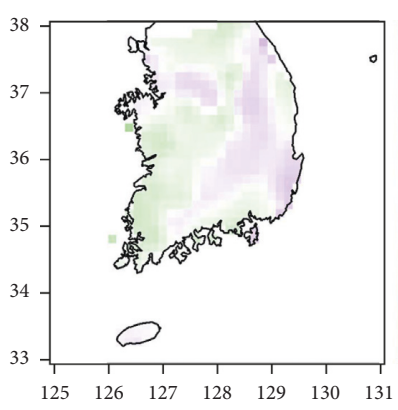

(h)

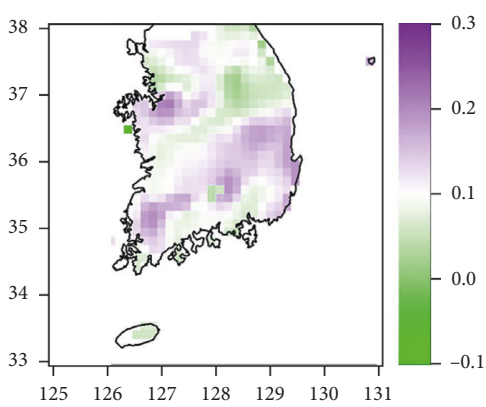

(c)

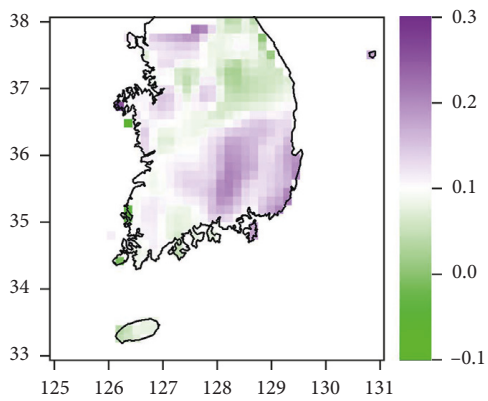

(f)

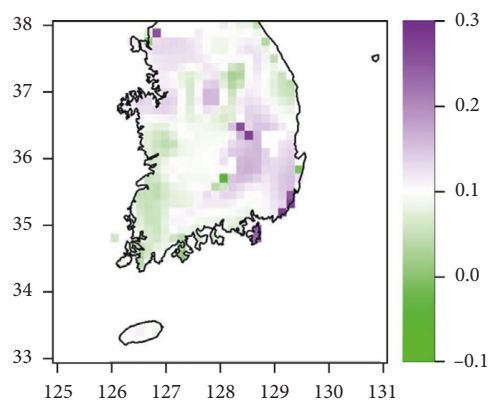

(i)

FIGURE 4: Coefficient of variation of 20-year return value of annual maximum daily precipitation for CMIP5 26 GCMs corrected by SDQM ((a), (b), and (c)), SD-DQM ((d), (e), and (f)), and SD-QDM ((g), (h), and (i)) for the reference ((a), (d), and (g)), Future3 period ((b), (e), and $(\mathrm{h}))$, and the difference between reference and Future3 period in percentage ((c), (f), and (i)).

TABle 3: Coefficient of variation of 20-year precipitation under reference, Future1, Future2, and Future3 period for South Korea.

\begin{tabular}{lcccccccccccc}
\hline & \multicolumn{3}{c}{ Reference } & \multicolumn{3}{c}{ Future1 } & \multicolumn{3}{c}{ Future2 } & \multicolumn{3}{c}{ Future3 } \\
& SDQM & SD-DQM & SD-QDM & SDQM & SD-DQM & SD-QDM & SDQM & SD-DQM & SD-QDM & SDQM & SD-DQM & SD-QDM \\
\hline Avg. & 0.132 & 0.132 & 0.148 & 0.235 & 0.228 & 0.216 & 0.235 & 0.249 & 0.237 & 0.234 & 0.240 & 0.243 \\
Med. & 0.128 & 0.128 & 0.141 & 0.226 & 0.222 & 0.204 & 0.234 & 0.240 & 0.232 & 0.235 & 0.236 & 0.238 \\
\hline
\end{tabular}

period were all small and similar spatially, so the difference map (Figure 4(c), 4(f), and 4(i)) followed the results of Future3 period (Figure 4(b), 4(e), and 4(h)).

The uncertainty was investigated by calculating the $\mathrm{CV}$ of climate change scenarios according to the downscaling methods. Table 3 shows that the coefficient of variation in future climate is larger than in the reference climate which may be mainly due to internal variability. In the future climate, the variation according to downscaling methods was not clear. As shown in Figure 4, although the difference in the magnitude of the CV between the methods is not clear, large values of CV become widespread with time (Table 3).
3.2. Probability Density Function. The averages of 20 -year precipitation increased over time, and the region where the $\mathrm{CV}$ was increasing in Figure 4 was larger during the further future. This trend was also confirmed by analyzing the changes in the probability distribution. Figure 5 shows the parameters and return periods of the GEV distribution for the extreme precipitation of the 26 climate models during the reference and future periods. Each subfigure in Figure 5 represents the parameter of GEV distribution of extreme precipitation downscaled with SDQM, SD-DQM and SDQDM, respectively, and a change projection of 20-year precipitation in the reference period. 

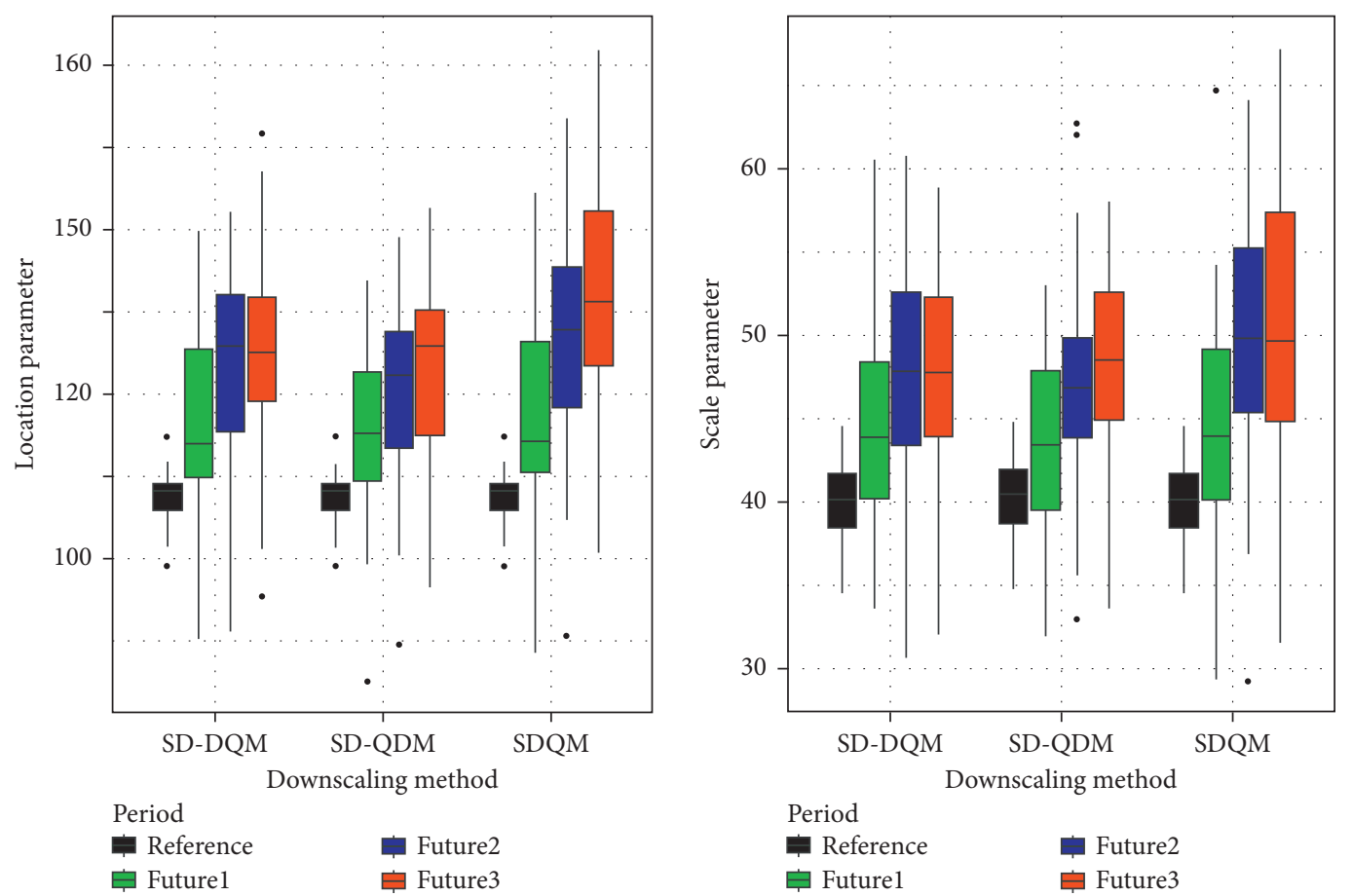

(a)

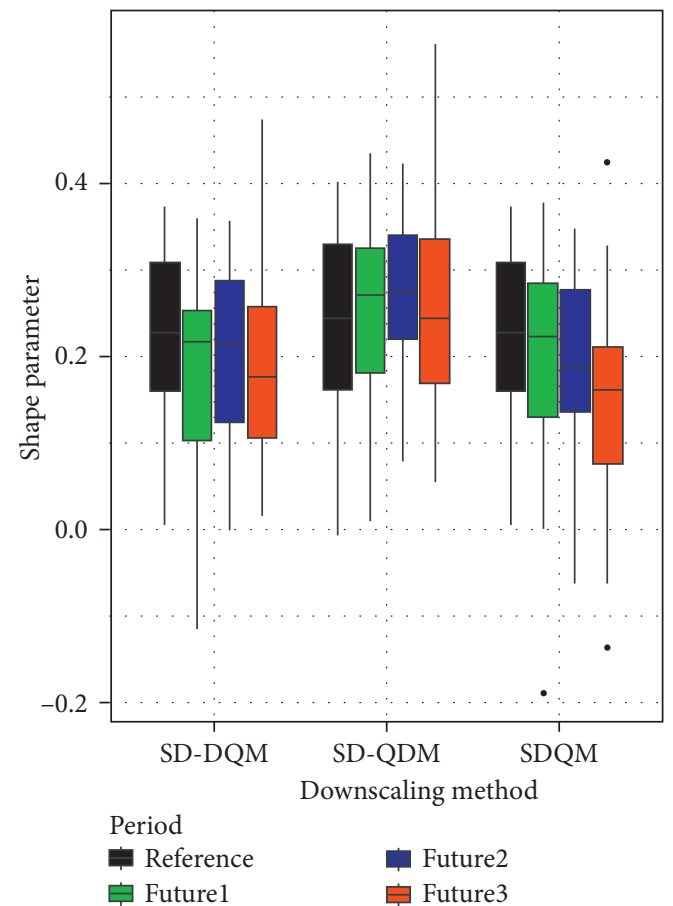

(b)

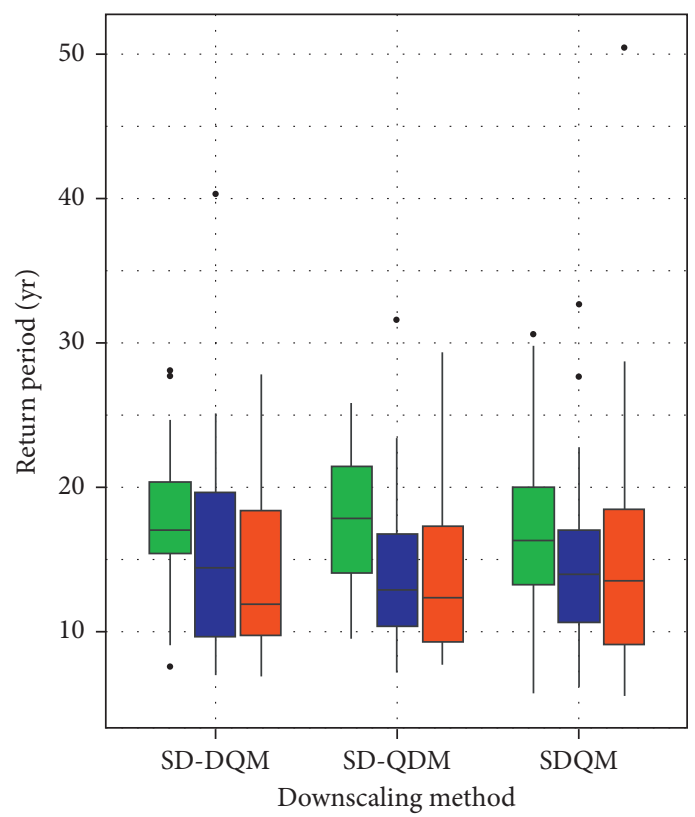

Period

官 Future1

Future2

Future3

(c)

(d)

Figure 5: Box-plot of (a) location, (b) scale, (c) shape parameter of GEV distribution for CMIP5 precipitation, and (d) return period of future for 20-year precipitation of reference climate.

TABLe 4: Return periods of Future1, Future2, and Future3 using 20-year precipitation of reference climate as shown in Figure 5(d).

\begin{tabular}{lcccccccrr}
\hline & & Future1 & \multicolumn{3}{c}{ Future2 } & \multicolumn{3}{c}{ Future3 } \\
& QM & DQM & QDM & QM & DQM & QDM & QM & DQM & QDM \\
\hline Avg. & 16.93 & 17.39 & 17.47 & 14.18 & 14.85 & 14.80 & 15.04 & 14.71 \\
Med. & 16.30 & 16.63 & 16.76 & 13.90 & 14.21 & 14.16 & 13.49 & 12.68 & 12.28 \\
\hline
\end{tabular}




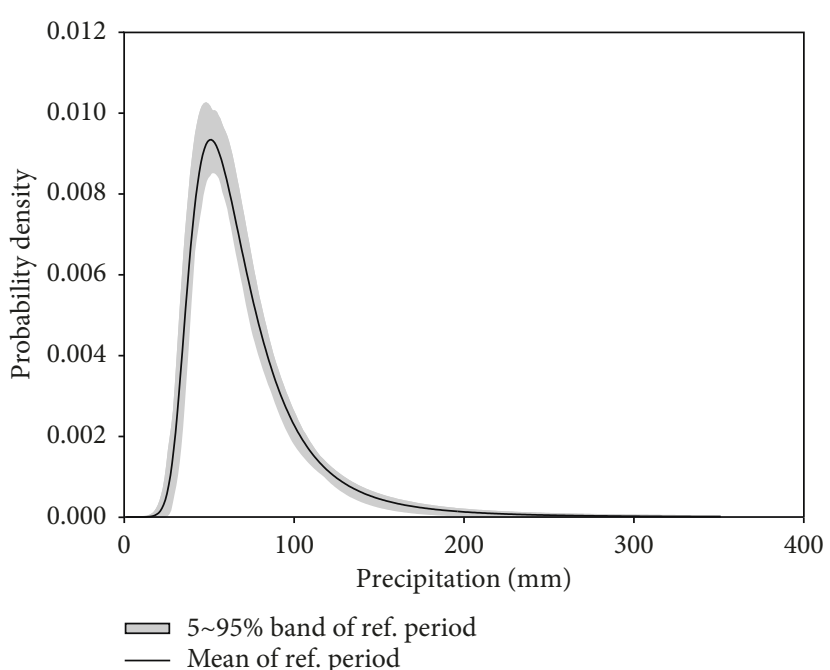

(a)

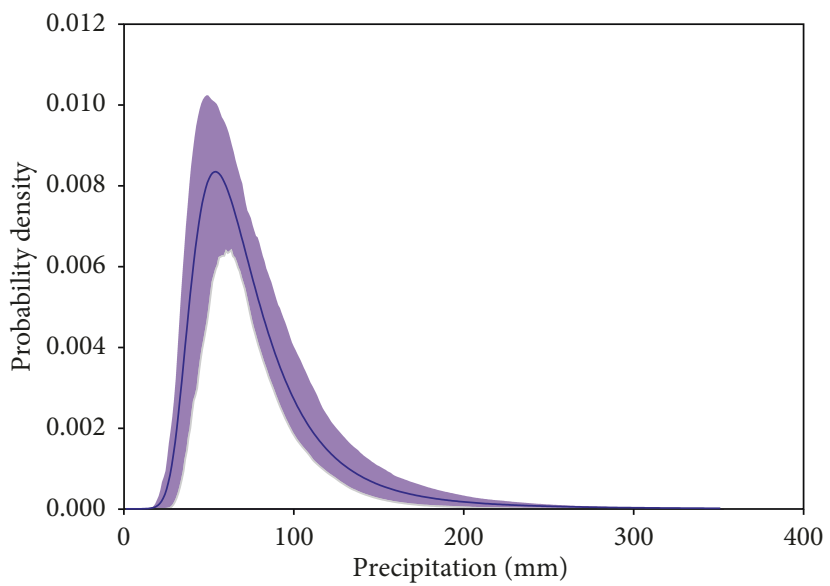

5 95\% band of Future2 — Mean of Future2

(c)

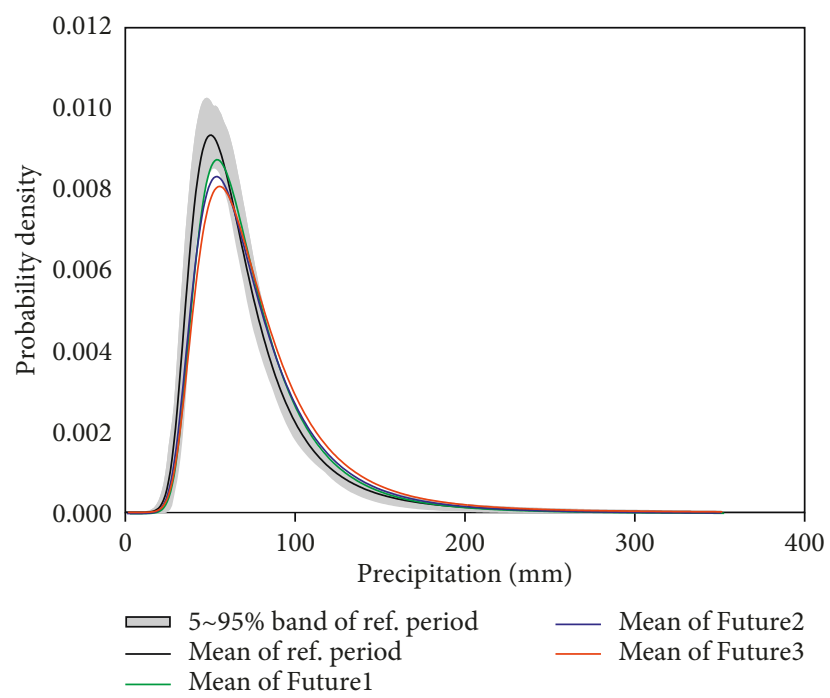

(e)

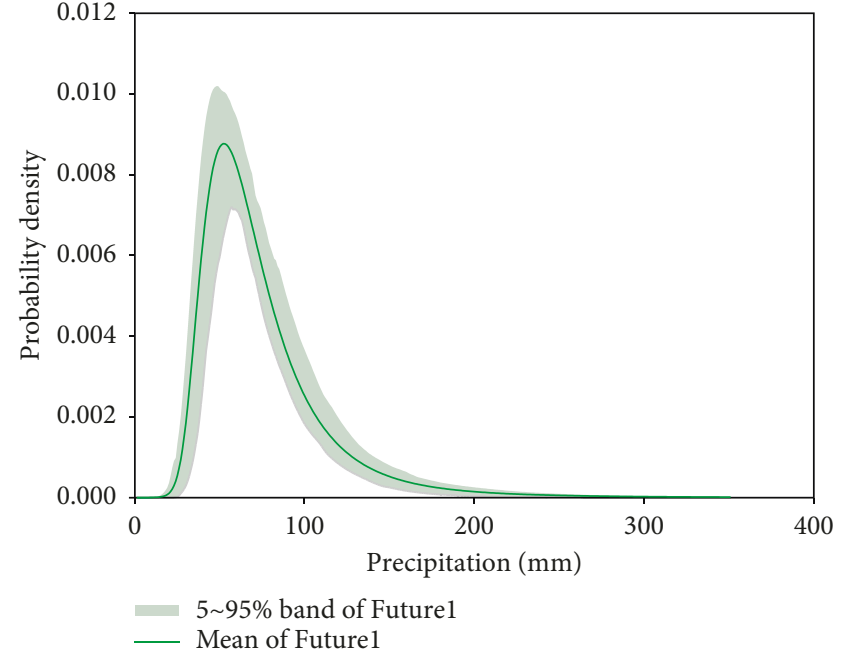

(b)

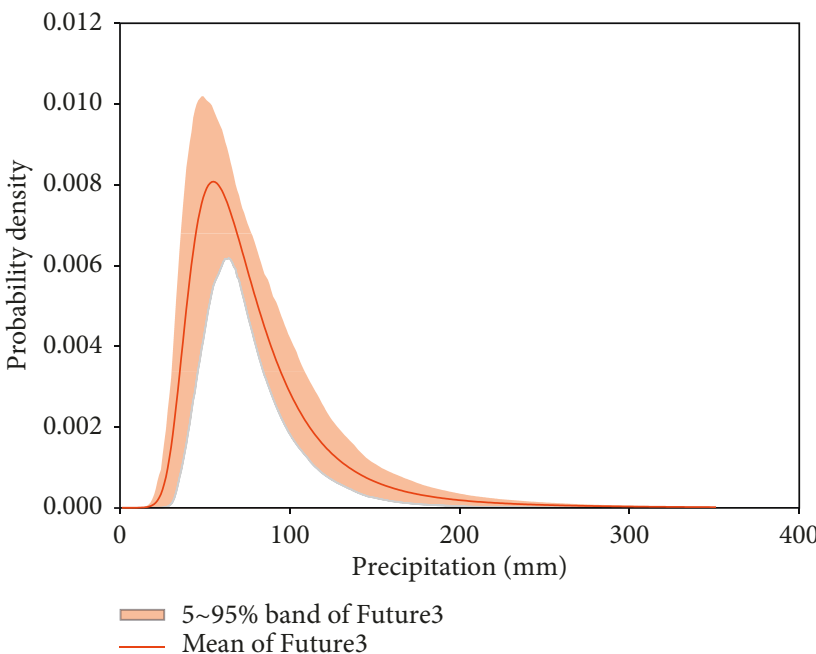

(d)

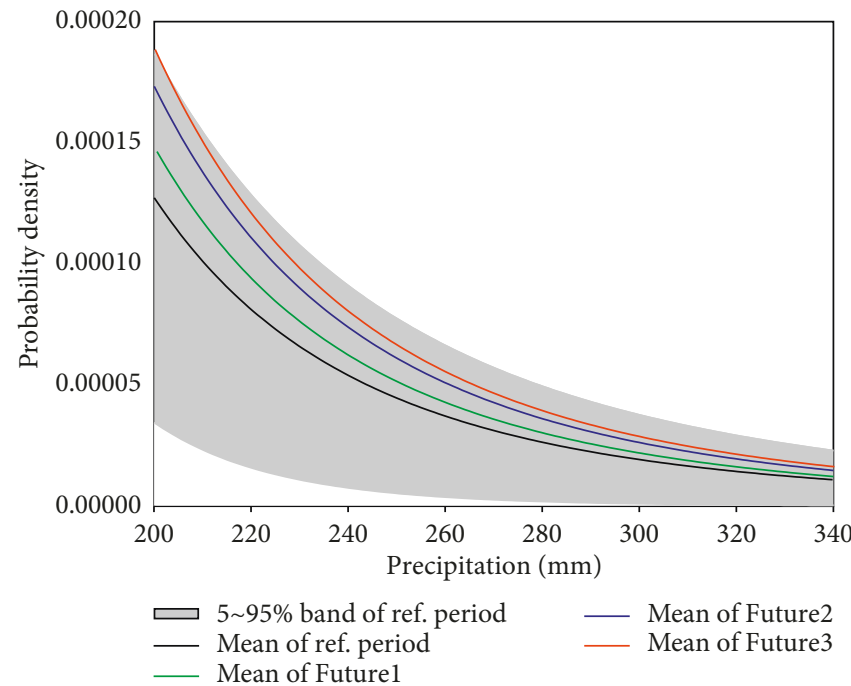

(f)

FIGURE 6: GEV probability density functions considering all downscaling methods for (a) reference, (b) Future1, (c) Future2, (d) Future3 period, (e) all together, and (f) zoomed Figure 6(e) for extreme values. 
Location and scale parameters increased monotonously as shown in Figure 5. They were increasing in future climate compared to reference climate, but there was no big difference between Future2 and Future3. There was no difference in shape parameters over the periods. In recent studies on the nonstationary probability distribution model, the shape parameter has become smaller overall, indicating that the right tail of the GEV probability density function becomes thicker and the occurrence of extreme precipitation becomes more frequent in the future [42]. The median of the return period estimated by the inverse of the GEV distribution is expected to be decrease from the reference 20-year to the Future1: 16.56yr; Future2: $14.09 \mathrm{yr}$; and Future3: $12.82 \mathrm{yr}$ (Table 4 ), which means that 20 -year precipitation of the reference climate would be relatively frequent in the future. However, it should be noted that this result is only the result of using RCP 4.5. This study used a single scenario to investigate the changes in future prospects closely. However, since we cannot be certain of which of scenarios will be realized, the actual uncertainty is larger than that shown in Figure 6, particularly in the later future.

Changes in GEV-PDFs of reference and future climate were analyzed in Figure 6 . The black lines and gray bands are the mean and confidence intervals (5 95\%) of the PDFs of the reference climate. The confidence interval corresponds to the upper $95 \%$ and $5 \%$ of the 26 climate models. The green solid line and band mean the PDFs for Future1, the blue solid line and band for Future2, and the red solid line and band for Future3 (Figure 6(a) 6(d)). Figures 6(e) and 6(f) illustrate the change in GEV distribution in the future climate relative to the reference climate, and the PDFs shifted to the right and the right tail thickened over time. In addition, we found that the PDFs of the future periods are located out of the $10 \%$ confidence interval of the PDF for the reference period, which presents a significant difference of PDFs between the reference and future periods. The result indicates that the design standard under the reference climate is not managed to cope with climate change, and accordingly the revision of the design standard is required to improve sustainability in infrastructures.

\section{Conclusion and Summary}

This study investigated changes of extreme precipitation over time using the 26 CMIP5 climate models under RCP 4.5 , which were statistically downscaled by three methods frequently used in climate change impacts assessment. The ensemble average 20-year return value of precipitation was projected to increase while the coefficient of variation of this return value within the ensemble expanded in the future. In other words, the uncertainty of the models increased over time and the extreme precipitation events may be more severe in the future as a whole. For the case of using the SDQDM downscaling method, 20-year precipitation in the period 2071-2100 was estimated to increase to $350 \mathrm{~mm}$, $121.5 \%$ compared to the reference climate, and especially in the south, east coast and metropolitan areas. Because the recent summer precipitation of South Korea has been dominated by unstable convective activity, typhoon, and low pressure, there was much precipitation in the middle and coast of the Youngdong, the southern coast, the eastern region of Jeju, and the northern region of Gyeonggi-do [43]. Our results are consistent with these trends.

Although the confidence interval of the PDF of GEV widened over time, which means the uncertainty also increased over time. However, due to the increasing trend of location and scale parameter and the decreasing trend of shape parameter, the PDF moved to the right, and the upper tail was expected to be thicker. However, the downscaled extreme precipitation showed considerable variability between the models and between the downscaling methods in this study. This means that simulation of extreme precipitation is dependent on each resolution and parameterization. This leads to the limit in the quantitative projection of extreme precipitation based on climate change scenarios. Nevertheless, the future PDF is located outside of the $10 \%$ confidence interval of the reference PDF, so it was confirmed that the revisit of the design standard was required. There is limitation to not provide acceptable methodology for design standard revision. Sen et al. [44] provided methodology for design standard revision. In the future, we will examine the performance of engineering structure based on including the climate change factor in the risk calculation formulation.

\section{Conflicts of Interest}

The authors declare that they have no conflicts of interest.

\section{Acknowledgments}

This work was supported by the Korea Agency for Infrastructure Technology Advancement (KAIA) grant funded by the Ministry of Land, Infrastructure and Transport (Grant 18AWMP-B083066-05).

\section{References}

[1] A. L. Kay, H. N. Davies, V. A. Bell, and R. G. Jones, "Comparison of uncertainty sources for climate change impacts: flood frequency in England," Climatic Change, vol. 92, no. 1-2, pp. 41-63, 2009.

[2] C. Prudhomme and H. Davies, "Assessing uncertainties in climate change impact analyses on the river flow regimes in the UK. Part 2: future climate," Climatic Change, vol. 93, no. 12, pp. 197-222, 2009.

[3] R. L. Wilby and I. Harris, "A framework for assessing uncertainties in climate change impacts: low-flow scenarios for the River Thames, U.K.," Water Resources Research, vol. 42, no. 2, article W02419, 2006.

[4] D. M. Wolock and G. J. McCabe, "Estimates of runoff using water-balance and atmospheric general circulation models," Journal of the American Water Resources Association, vol. 35, no. 6, pp. 1341-1350, 1999.

[5] F. J. Doblas-Reyes, R. Hagendorn, and T. N. Palmer, "The rationale behind the success of multi-model ensembles in seasonal forecasting-II. Calibration and combination," Tellus A: Dynamic Meteorology and Oceanography, vol. 57, no. 3, pp. 234-252, 2005.

[6] F. Giorgi and L. O. Mearns, "Calculation of average, uncertainty range, and reliability of regional climate changes 
from AOGCM simulations via the "Reliability Ensemble Averaging" (REA) method," Journal of Climate, vol. 5, pp. 1141-1158, 2002.

[7] J. K. Lee, Y.-O. Kim, and Y. Kim, "A new uncertainty analysis in the climate change impact assessment," International Journal of Climatology, vol. 37, no. 10, pp. 3837-3846, 2016.

[8] IPCC, Climate Change 2014: Mitigation of Climate Change. Working Group III Contribution to the Fifth Assessment Report of the Intergovernmental Panel on Climate Change, Cambridge University Press, Cambridge, UK, 2014.

[9] A. E. Raftery, T. Gneiting, F. Balabdaoui, and M. Polakowski, "Using Bayesian model averaging to calibrate forecast ensemble," Monthly Weather Review, vol. 133, pp. 1155-1174, 2005.

[10] J. Raisanen and T. N. Palmer, "A probability and decisionmodel analysis of a multimodel ensemble of climate change simulation," Journal of Climate, vol. 14, pp. 3212-3226, 2001.

[11] B. Rajagopalan, U. Lall, and S. E. Zebiak, "Categorical climate forecasts through regularization and optimal combination of multiple GCM ensembles," Monthly Weather Review, vol. 130, pp. 1792-1811, 2002.

[12] E. S. Im, B. J. Lee, J. H. Kwon, S. R. In, and H. O. Han, "Potential increase of flood hazards in Korea due to global warming from a high-resolution regional climate simulation," Asia-Pacific Journal of the Atmospheric Sciences, vol. 48, pp. 107-113, 2012.

[13] J. H. Sung, H. S. Kang, S. Park, C. Cho, D. H. Bae, and Y.-O. Kim, "Projection of extreme precipitation at the end of 21st century over South Korea based on Representative Concentration Pathways (RCP)," Atmosphere, vol. 22, no. 2, pp. 221-231, 2012, in Korean.

[14] J. B. Ahn, S.-R. Jo, M.-S. Suh, and K.-M. Shim, "Changes of precipitation extremes over South Korea projected by the 5 RCMs under RCP scenarios," Asia-Pacific Journal of the Atmospheric Sciences, vol. 52, no. 2, pp. 223-236, 2016.

[15] E. S. Im, J. B. Ahn, and S. R. Jo, "Regional climate projection over South Korea simulated by the HadGEM2-AO and WRF model chain under RCP emission scenarios," Climate Research, vol. 63, pp. 249-266, 2015.

[16] D. H. Cha and D. K. Lee, "Reduction of systematic errors in regional climate simulations of the summer monsoon over East Asia and the western North Pacific by applying the spectral nudging technique," Journal of Geophysical Research, vol. 114, article D14108, 2009.

[17] F. Giorgi and L. O. Mearns, "Introduction tospecial section: regional climate modeling revisited," Journal of Geophysical Research, vol. 104, pp. 6335-6352, 1999.

[18] D. K. Lee and M. S. Suh, "Ten-year east Asian summer monsoon simulation using a regional climate model (RegCM2)," Journal of Geophysical Research, vol. 105, no. 22, pp. 29565-29577, 2000.

[19] M. S. Suh, S. G. Oh, D. K. Lee et al., "Development of new ensemble methods based on the performance skills of regional climate models over South Korea," Journal of Climate, vol. 25, pp. 7067-7082, 2012.

[20] J. T. Abatzoglou and T. J. Brown, "A comparison of statistical downscaling methods suited for wildfire applications," International Journal of Climatology, vol. 32, no. 5, pp. 772-780, 2012.

[21] G. Burger, S. R. Sobie, A. J. Cannon, A. T. Werner, and T. Q. Murdock, "Downscaling extremes: an Intercomparison of multiple methods for future climate," Journal of Climate, vol. 26, pp. 3429-3449, 2013.
[22] A. J. Cannon, S. R. Sobie, and T. Q. Murdock, "Bias correction of GCM precipitation by quantile mapping: how well do methods preserve changes in quantiles and extremes?," Journal of Climate, vol. 28, pp. 6938-6959, 2015.

[23] I. Dabanlı and Z. Şen, "Precipitation projections under GCMs perspective and Turkish Water Foundation (TWF) statistical downscaling model procedures," Theoretical and Applied Climatology, vol. 132, no. 1-2, pp. 153-166, 2017.

[24] H.-I. Eum and A. J. Cannon, "Intercomparison of projected changes in climate extremes for South Korea: application of trend preserving statistical downscaling methods to the CMIP5 ensemble," International of Journal of Climatology, vol. 37, no. 8, pp. 3381-3397, 2017.

[25] A. W. Wood, L. R. Leung, V. Sridhar, and D. P. Lettenmaier, "Hydrologic implications of dynamical and statistical approaches to downscaling climate model outputs," Climatic Change, vol. 62, pp. 189-216, 2004.

[26] D. G. Groves and R. J. Lempert, "A new analytic method for finding policy-relevant scenarios," Global Environmental Change, vol. 17, pp. 73-85, 2007.

[27] M.-J. Shin, H.-I. Eum, C.-S. Kim, and I.-W. Jung, “Alteration of hydrologic indicators for Korean catchments under CMIP5 climate projections: alteration of hydrologic indicators for the seven Korean catchments," Hydrological Processes, vol. 30, no. 24, pp. 4517-4542, 2016.

[28] S. Hwang and W. D. Graham, "Development and comparative evaluation of a stochastic analog method to downscale daily GCM precipitation," Hydrology and Earth System Sciences, vol. 17, no. 11, pp. 4481-4502, 2013.

[29] D. Shepard, "A two-dimensional interpolation function for irregularly-spaced data," in Proceedings of the 1968 ACM National Conference, New York, USA, 1968.

[30] D. Maraun, "Bias correction, quantile mapping, and downscaling revisiting the inflation issue," Journal of Climate, vol. 26, no. 6, pp. 2137-2143, 2013.

[31] E. P. Maurer and D. W. Pierce, "Bias correction can modify climate model simulated precipitation changes without adverse effect on the ensemble mean," Hydrology and Earth System Sciences, vol. 18, no. 3, pp. 915-925, 2014.

[32] R. W. Katz, M. B. Parlange, and P. Naveau, "Statistics of extremes in hydrology," Advances in Water Resources, vol. 25, pp. 1287-1304, 2002.

[33] V. V. Kharin and F. W. Zwiers, "Estimating extremes in transient climate change simulations," Journal of Climate, vol. 18, no. 8, pp. 1156-1173, 2005.

[34] V. V. Kharin, F. W. Zwiers, and X. Zhang, "Intercomparison of near surface temperature and precipitation extremes in AMIP-2 simulations, reanalyses, and observations," Journal of Climate, vol. 18, no. 24, pp. 5201-5223, 2005.

[35] J. J. Egozcue and C. Ramis, "Bayesian hazard analysis of heavy precipitation in eastern Spain," International Journal of Climatology, vol. 21, no. 10, pp. 1263-1279, 2001.

[36] R. L. Smith, Trends in Rainfall Extremes, University of North Carolina, Chapel Hill, NC, USA, 1999, In press.

[37] R. L. Smith, "Extreme value statistics in meteorology and environment," Environmental Statistics, Chapter 8, pp. 300-357, 2001.

[38] J. R. Stedinger, R. M. Vogel, and E. Foufoula-Georgiou, Frequency analysis of extreme events, Handbook of Hydrology, Chapter 18, D. R. Maidment, Ed., McGraw-Hill, New York, NY, USA, 1993.

[39] E. S. Martin and J. R. Stedinger, "Generalized maximum likelihood GEV quantile estimator for hydrologic data," Water Resources Research, vol. 28, no. 11, pp. 3001-3010, 2000. 
[40] A. M. G. Klein Tank, F. W. Zwiers, and X. Zhang, "Guidelines on analysis of extremes in a changing climate in support of informed decisions for adaptation," Climate Data and Monitoring, WCDMP-72, WMO-TD/No. 1500, p. 56, 2009.

[41] S. R. In, S. O. Han, E. S. Im, K. H. Kim, and J. Shim, "Study on temporal and spatial characteristics of summertime precipitation over Korean peninsula," Atmosphere, vol. 24, no. 2, pp. 159-171, 2014, in Korean.

[42] J. Park, J. H. Sung, Y.-J. Lim, and H.-S. Kang, "Introduction and application of non-stationary standardized precipitation index considering probability distribution function and return period," Theoretical and Applied, 2018.

[43] C. Park, J. Moon, E.-J. Cha, W.-T. Yun, and Y. Choiz, "Recent changes in summer precipitation characteristics over South Korea," Journal of the Korean Geographical Society, vol. 43, no. 3, pp. 324-336, 2008, in Korean.

[44] Z. Sen, M. A. Mohorji, and M. Almazroui, "Engineering risk assessment on water structures under climate change effects," Arabian Journal of Geosciences, vol. 10, p. 517, 2017. 

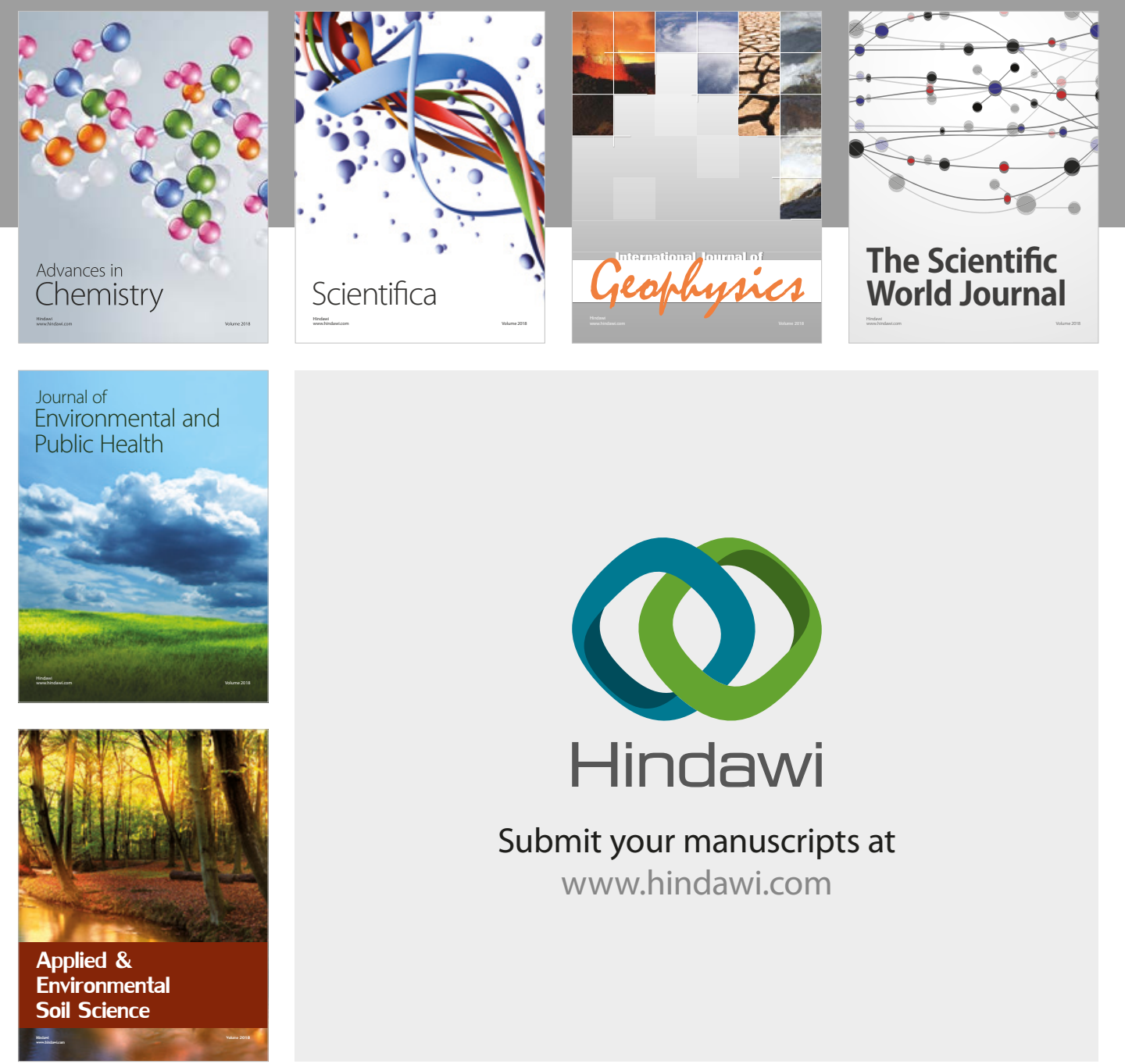

The Scientific

\section{World Journal}
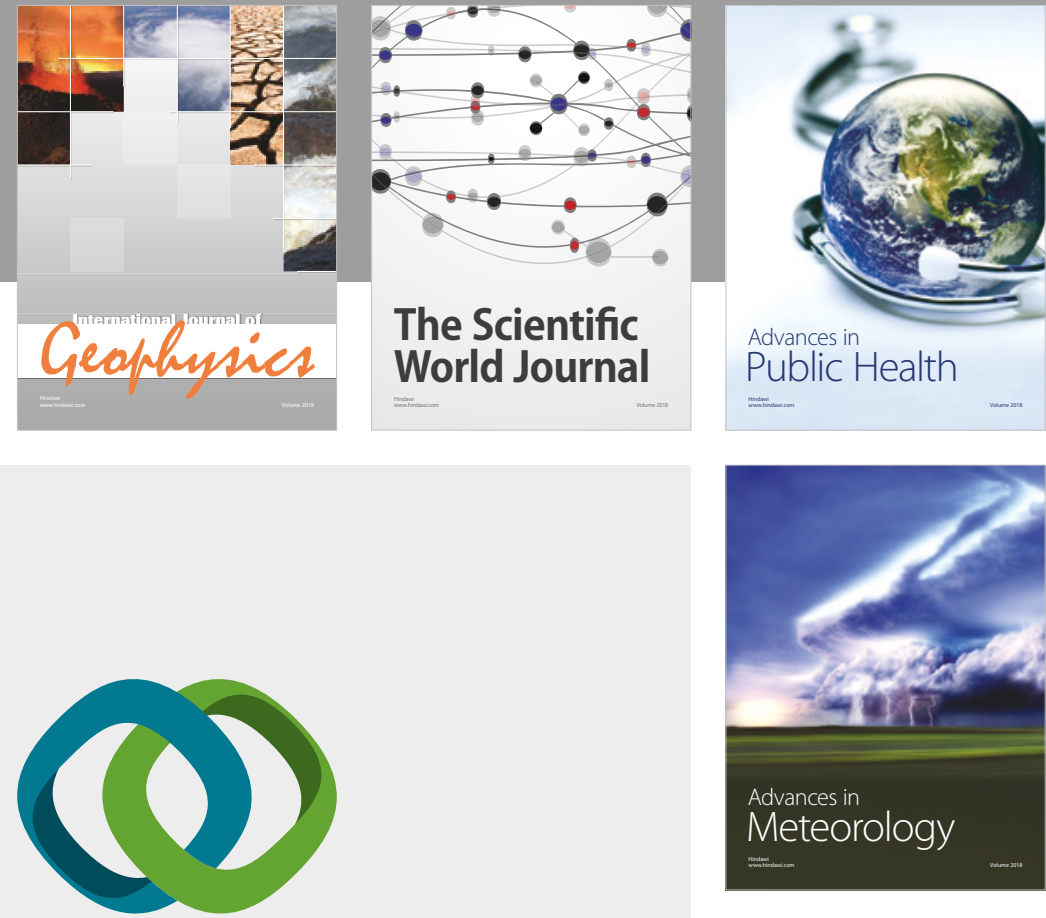

Advan

Public Health

\section{Hindawi}

Submit your manuscripts at

www.hindawi.com
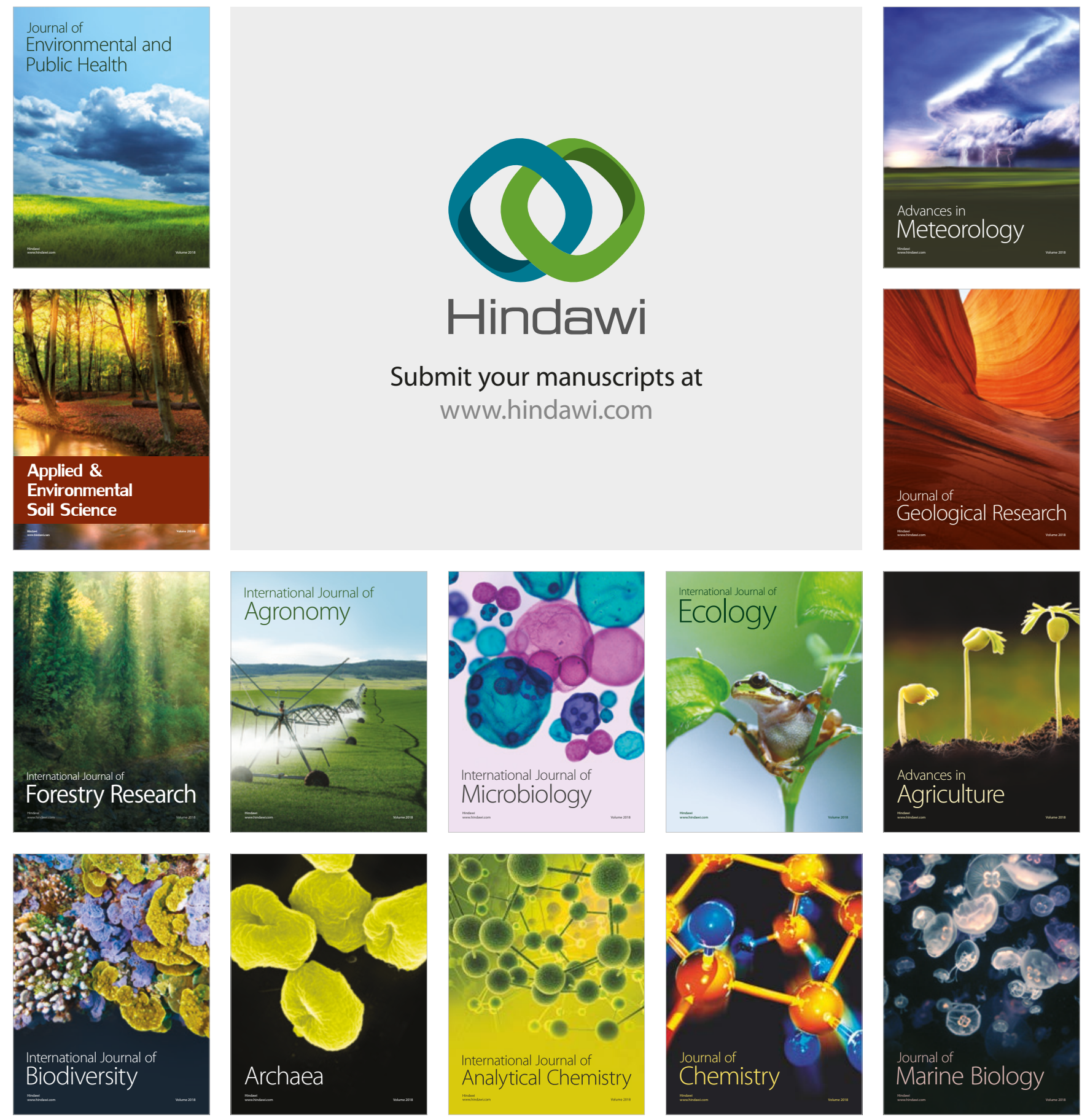